\title{
Transmission Constraints Impacts On Monopolistic Production Capacity under Strategic Bidding
}

\author{
Abouzar Estebsari*, Seyyed Mohammad Sadeghzadeh**, and Mohammad Ali Fotouhi*** \\ * MSc Graduated, Faculty of Engineering, Shahed University, Tehran, Iran \\ ** Assoiate Professor , Faculty of Engineering, Shahed University, Tehran, Iran \\ *** MSc Student, Faculty of Electrical Engineering, K. N. Toosi University, Tehran, Iran
}

\begin{abstract}
In power systems, transmission network constraints and losses can introduce gross distortions in the market for electrical energy. Congestion occurs frequently in weakly connected networks and may split a market into regions unable to compete properly with each other.

The oligopoly structure of the market and the network constraints may produce results far from the perfect competition. This may cause lack of cheap energy in some areas and surplus in others. Consideration of market power caused by congestion is the main aids of our paper. We have used a methodology in order to evaluate any events that are suspected to have any relation to the market power. Since some participants have the ability to raise prices without losing market share, we should identify them and determine the amount of this energy. Bidding strategies, such as withholding capacity and bidding at higher price, influence the network and cause transmission congestion. The methodology was tested on IEEE 30 buses standard system by some indices such as HHI and Lerner index, finally the results of identification have been confirmed. For this simulation MATPOWER version 3.2 was used as OPF solver using both AC and DC power flow representation.
\end{abstract}

Keywords: Electricity markets, market performance indices, monopoly, Transmission constraints.

\section{INTRODUCTION}

Electricity markets recently have been involved in serious restructuring aimed at promoting competition among market participants[1]. The assumption in this paper is a pool system. Electricity pool is a contractual arrangement entered into by generators and suppliers that provides the wholesale market mechanism for trading electricity. The electricity pool does not itself act as market maker buying or selling electricity but instead facilitates a competitive bidding process between generators that sets the wholesale price paid for electricity for every period of every day. It also establishes the preferred generation merit order at the day-ahead stage. Transmission constraints and losses in the network connecting these generators and loads can introduce gross distortions in the market for electrical energy [3]. If the number of participants in a market is large enough, no parties can control a large proportion of production and consumption. In other words, suppliers who ask for more than market price and consumers who offer less than market price can simply be ignored as they can be easily replaced by other participants in a perfectly competitive market. However, if the number of participants is not large enough, there might be some producers and consumers that are able to control the share of the market that is large enough to exercise market power.

Market power is defined as the ability to alter profitably prices away from competitive level (Mas-Collel et al. 1995). Market power can be exercised either by withholding the quantity of commodity or by raising the asking price above the competitive price level without affecting the demand of the commodity. In power systems, transmission network provides the infrastructure to support a competitive electricity market, but congestion occurs frequently in weakly connected networks. In a competitive electricity market, the oligopoly structure of the market and the network constraints may produce results far from the perfect competition.

(MSC) of California ISO identified major market design flaws. These flaws were presented to FERC and California Public Utilities Commission but nobody took any action on them. Two years later the producer's exercise of unilateral market power began to result in significant wealth transfer, but still FERC took no actions. Although warnings were repeated in subsequent MSC reports and a number of remedies were suggested, it took until January 1, 2001, before FERC took action in limiting the circumstance. And when they finally did they failed. Instead of limiting the case, these "remedies" rather enhanced suppliers to exploit market power. What happened next is what people refer to as the "California crisis". After the implementation date, average spot prices rose to over $\$ 300 / \mathrm{MWh}$ and the first period of rolling blackouts immediately followed. So prospective market monitoring seems really necessary.

One of the main objectives in the market monitoring process is the analysis of market power issues. The path toward liberalization has been undertaken under the belief that the competition would strive for market efficiency [5] and price reduction resembling to the microeconomic model of perfect competition in which the social welfare would be the highest possible and the price the lowest. Unfortunately, different reasons may lead the market far from this desirable result. Some papers focus on the congestion impacts also in presence of the demand elasticity representation and the reactive load modeling [6], [7], [8] and provide methods to alleviate congestion impacts. In [9], the transmission congestion cost and locational marginal prices are considered, while in [10], thermal, voltage, and stability limits are considered to represent the feasibility region for the system. A Herfindahl-Hirschman index has been proposed as a sensitive signal of transmission congestion [11]. Strategic bidding has been extensively considered according to different approaches such as statistical approaches [12], [13], parametric dynamic programming [14], Lagrange relaxation [15], genetic algorithm [16], stochastic procedure [17], fuzzy set theory [18], and game theory [20][22]. In [23], the oligopolistic competition is examined in the submarkets that are isolated by constrained transmission lines.

This paper presents an approach for modeling bidding strategies behavior in a pool system and under network constraints like congestion in order to provide a way to calculate the remaining market shares and some tools for assessing transmission impacts on the market performances. This calculation will be done using both the DC and the AC 
power flow model. Using the AC model should give better results, since it is the more accurate model of reality, but it takes much more time (about 100 times).

This paper consists of 4 additional sections. In the next section the market power definitions are given. In part III the market monopoly and monopolistic competition are explained and the impact of network constraints on developing monopoly is described. In section IV some of widely used indexes of market power detection which are going to be used are introduced. The section $\mathrm{V}$ focus on introducing of monopolistic production capacity calculation algorithm and in the next part the results of simulations on a 30-bus IEEE system which is a bit alternated are shown. In section conclusion we discuss about the results and usages of this approach.

\section{MARKET POWER}

There are two main reasons why the potential of market power is brought to the electricity market. First there is market dominance and then there are transmission constraints [14]. Market power due to market dominance is a scenario that applies for every imperfect market and not only for the electricity market. On the electricity market, a supplier that is large enough to affect price can exploit market power by either economical withholding or physical withholding. When dealing with economical withholding a seller keeps bidding above the marginal cost of production and thereby driving up the price. Physical withholding simply means that a seller withholds some of its available capacity.

Market power due to transmission constraints makes it necessary to get a full understanding of the topology of the transmission system before starting any plan of detecting the potential for market power [15].

If a supplier is placed within a so called load pocket, this participant will have a local market power. A supplier in this case can find himself in a position of monopoly by intentionally create congestion and limit access of competitors. This means that, by getting dispatched at strategic points in the network, a supplier in a load pocket can gain profit even by increasing its generation rather than withholding it [16]. Conclusively, transmission constraints in the electricity market make it possible even for a small supplier to exploit market power.

In a Network loads can't be accurately forecasted and energy can't be stored economically. Demand and supply must be balance all the time in order to maintain the system frequency, voltage, stabilization standards; Kirchhoff's laws and impedance of the whole network determine the power flows in the system [17]. When there is congestion, generating capacity in congested area will be relative scarcity, so congestion results in locational market power and causes invalidation of the optimization of generating resources in the whole network.

The LMP represents the willingness to supply an additional MW of load at a particular location. It is useful to break the LMP into parts to distinguish between costs resulting from network losses and those resulting from network congestion. The LMP includes a reference cost of generation and relative costs of congestion and losses in the system:

$\mathrm{LMP}=($ generation marginal costs $)+($ congestion cost $)+$ (cost of marginal losses).

The generator marginal cost is taken from a specified reference generator in the system. The congestion cost represents the effect of congestion on the LMP relative to the reference generator marginal cost.

\section{MONOPOLY AND MONOPOLISTIC COMPETITION}

Monopolistic competition is a market structure where there are many firms (like a competitive market), but these firms have some market power (they are able to set price above MC profitably). A monopoly is the only supplier of a good for which there is no close substitute.

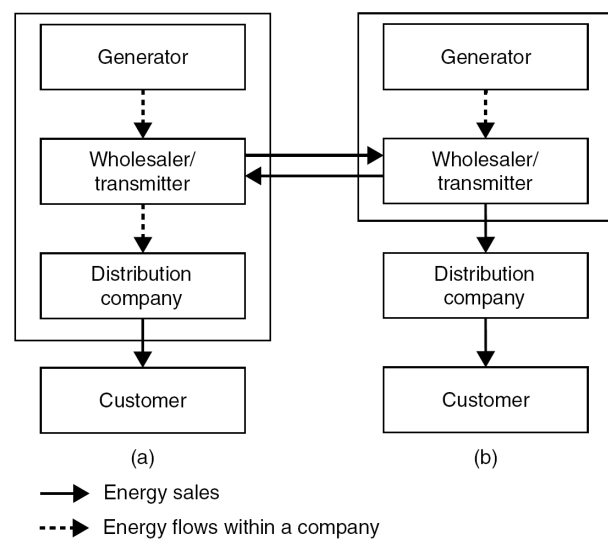

Fig 1. Monopoly model of electricity market based on (Hunt and Shuttle worth, 1996)

The Minimum Efficient Size (MES) of a firm in a particular industry provides a rough indication of the number of competitors that one is likely to find in the market for the product of this industry. This MES is equal to the level of output that minimizes the average cost for a typical firm in that industry. The shape of this curve is determined by the technology used to produce the goods. If, as illustrated in Figure 2(a), the MES is much smaller than the demand for the goods at this minimum average cost, the market should be able to support a large number of competitors. On the other hand, if, as shown in Figure 2(b), the MES is comparable to the demand, the market cannot support two profitable firms and a monopoly situation is likely to develop.
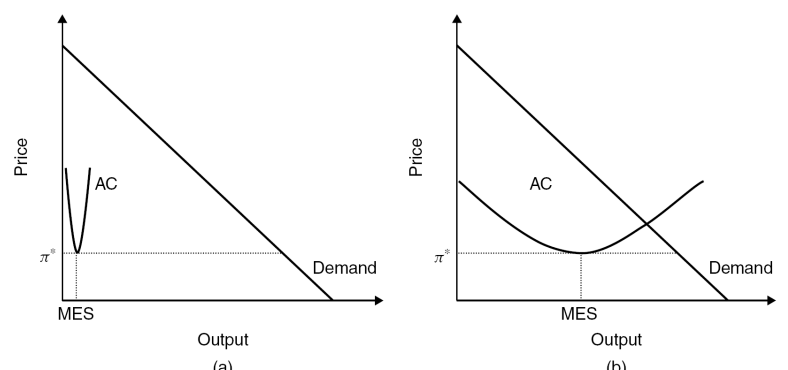

Fig 2. Concept of MES. (a) Competitive market, (b) Monopoly situation

Transmission is a natural monopoly. It is currently almost inconceivable that a group of investors would decide to build a completely new transmission network designed to operate in competition with an existing one. Because of their visual impact on the environment, it is indeed most unlikely that the construction of competing transmission lines along similar routes would be allowed. Furthermore, the minimum efficient size of a transmission network is such that electricity transmission is considered a good example of a natural monopoly.

In general, network constraints increase opportunities for strategic bidding because not all generators are connected in locations where they can relieve a given constraint. In many 
cases, the number of generators that can effectively affect a constraint is small. Congestion in the transmission network can therefore transform a reasonably competitive global market into a collection of smaller local energy markets. Since these smaller markets inevitably have fewer active participants than the global market, some of them are likely to be able to exert market power. Such scenarios are not easy to detect or analyze.

\section{INDICES}

Many different indexes have been proposed as measures of the electricity market's Competitiveness. Here we explain some of widely used indexes of market power detection which are going to be used.

\section{A. Efficiency and Allocation Indices}

The efficiency and allocation indices are expressed in percentage and have the general form:

\section{$\mathrm{S}$ : Social surplus}

$\mathrm{S}^{*}$ : We will use the superscript * for the values associated with the unconstrained market under perfect competition.

$$
K_{s}=\frac{S-S^{*}}{S^{*}}=\frac{\Delta S}{S^{*}} \times 100 .
$$

\section{B. Lerner Index:}

The exercise of market power results in a market price that is greater than both the competitive price and the marginal cost of production. The most common measure of this difference is the price-cost margin, also called the Lerner index (Stoft, 2002). The Lerner index is named after the economist Abba Lerner. It describes a monopoly's amount of market power. The mathematical formula is:

$$
\mathrm{L}=(\mathrm{P}-\mathrm{MC}) / \mathrm{P}
$$

Where $\mathrm{P}$ is competitive price and $\mathrm{MC}$ is marginal cost.

\section{Herfindahl Hirschman Index}

The HHI-index is a widely used standard measure of market concentration. It is a function of the number of companies in a market and their respective market shares. The calculation is done by summing the squares of all individual companies' market share percentages.

$$
\begin{aligned}
H H I= & \sum_{i}\left(\text { Company }_{i} \text { market share in } \%\right)^{2} \\
& H H I<1000 \rightarrow \text { Market is not concentrated } \\
1000< & H H I<1800 \rightarrow \text { Market is moderately concentrated } \\
& H H I>1800 \rightarrow \text { Market is highly concentrated }
\end{aligned}
$$

Group Herfindahl Hirschman Index:

$$
H H I_{G}=\sum_{i=1}^{m}\left[\frac{M W H_{i}}{\text { Total }_{G}} \times 100\right]^{2}
$$

$M W H_{i}:$ Production of unit I in the group

$\operatorname{Total}_{G}:$ Total production in the group

System Herfindahl Hirschman Index:

$$
\begin{aligned}
& H_{s}=\sqrt{\sum_{j=1}^{n}\left[\frac{M W H_{j}}{\text { Total }_{s}} \times H H I_{G j}^{2}\right]} \\
& M W H_{j}: \text { Total production in group } \mathrm{j} \\
& \text { Total }_{s}: \text { Total production of the system }
\end{aligned}
$$

$H H I_{G j}$ : Group j Herfindahl Hirschman Index

\section{MONOPOLISTIC PRODUCTION CAPACITY}

Energy supplying companies may be accountable for having monopolistic potential, even though there are several other suppliers openly competing with them on the market. Monopolistic Production Capacity is the amount of real power in MW that a single generator cannot be substituted for by any other competitor. It is, under the assumption of totally inelastic load, the amount of real power that the supplier or group of suppliers, e.g. a generation company, could demand any price for. For example if all generators of the market are owned by a single company (monopoly), then the total load in MW would also be the Monopolistic Production Capacity for that company. To calculate this capacity the main procedure uses OPF in DC or AC models. By increasing some of generators' bidding prices, we find that a part of the production capacity of these generators will not be reduced. Among the offers submitted from all the generators there is a certain generator who is offering its energy at an extremely high price compared to all other generators on the market. The optimal solution to this problem would be to exclude this generator from getting scheduled. This approach is very straightforward and in simple network cases it would be quite possible to calculate MPC ${ }^{1}$ by hand, but for a bigger network (a real network) this would be a tough task without the aid of an optimization tool.

To calculate MPC for a given network the following is needed:

- Knowledge of locations and levels of available generation capacities.

- Knowledge of locations and levels of demand in the network.

- A program able to solve an Optimal Power Flow problem, using either the $\mathrm{DC}$ or the $\mathrm{AC}$ power flow model.

\section{Calculation Algorithm}

If the previously mentioned information is available we can use the following algorithm [19]:

1. Solve the OPF problem using an auction where all available capacities are offered at identical prices.

2. Save the vector of optimal dispatch $\bar{P}^{*}$ and the vector of LMPs $\bar{\lambda}^{*}$ that are valid in the buses where the generators are located.

3. Formulate a new OPF problem where the same available capacities are offered at each generator's corresponding LMP, given by the elements of $\bar{\lambda}^{*}$.

4. Before solving this newly formulated problem we raise the offered price of generator $i$ the following way:

$$
\lambda_{\text {inew }}=\lambda_{i}^{*}+\Delta \lambda \text {, }
$$

where $\Delta \lambda$ constitutes a "large" price increase.

5. Solve this second OPF problem.

6. Save the new vector of optimal dispatch $\bar{P}_{\text {new }}{ }^{*}$. In this vector the $i$ th element will represent the $i$ th generator's MPC.

7. Return to step 3 and continue this loop until all generators of interest have raised their price once.

For each loop in this algorithm a vector $\bar{P}_{n e w}{ }^{*}$ is saved. If $n$ generators are of interest, the algorithm will loop $n$ times, resulting in $n$ different $\bar{P}_{\text {new }}{ }^{*}$ vectors. Using these vectors we

\footnotetext{
${ }^{1}$ Monopolistic Production Capacity
} 
build the MPC matrix. In Equation 6.1 the resulting $n \times n$ matrix is illustrated.

$$
M P C=\left[\begin{array}{lll}
\bar{P}_{1 \text { st new }}^{*} & \bar{P}_{2 \text { nd new }}^{*} & \bar{P}_{\text {nth new }}^{*}
\end{array}\right]
$$

\section{SIMULATIONS}

\section{A. Electricity market monitoring}

Our case study system option is IEEE 30 buses network with twenty loads and six generators. The network is separated into three areas, each holding two generators. All transmission lines, except two of them, have a flow limit set to 200 MVA. The other two lines have a limit set to 10 MVA. These two lines constitute the only link between Area 2 and the rest of the network.

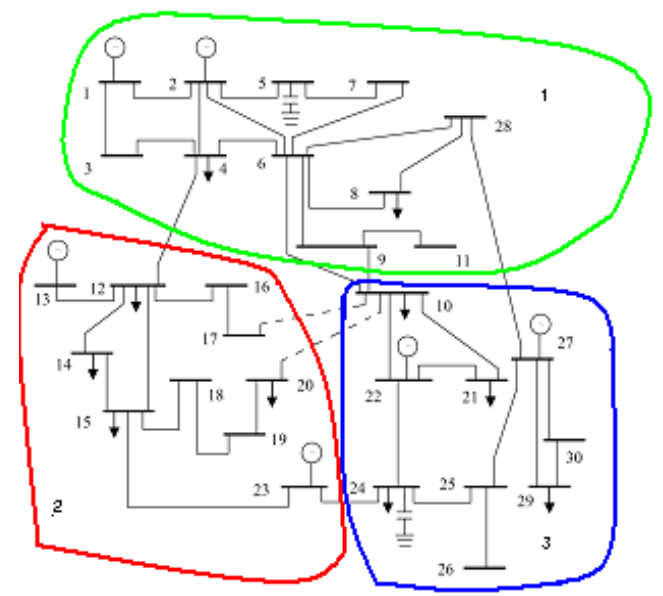

(a)

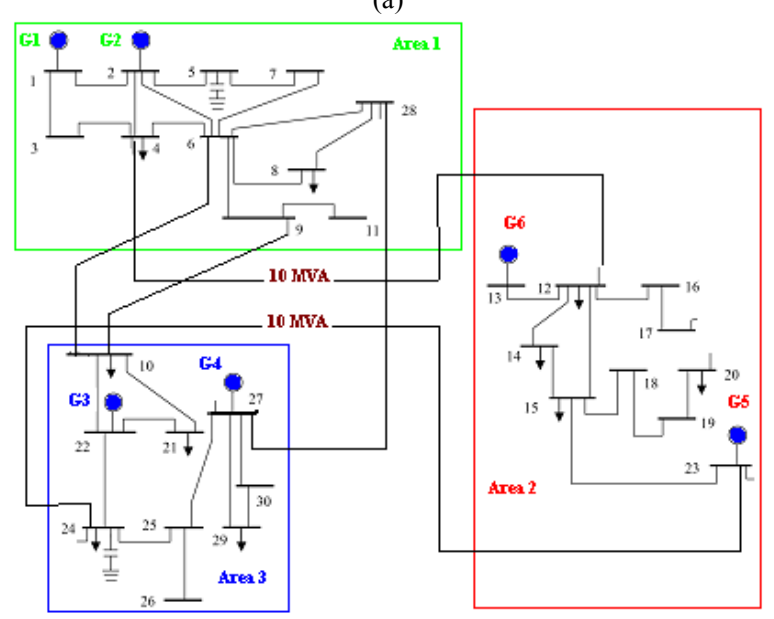

(b)

Fig 3. IEEE 30-bus system divided to 3 areas

Every generator in the network has a maximum capacity of real power set to $60 \mathrm{MW}$, this adds up to a total supply of 360MW. The total demand/load of $195 \mathrm{MW}$ is divided throughout the network in following way: Area 1 holds $50 \mathrm{MW}$, Area 2 has $85 \mathrm{MW}$, and Area 3, $60 \mathrm{MW}$. The load in each area is distributed equally over all busses.

All generators bid $60 \mathrm{MW}$ in 50\$/MW and the consumers offer in $70 \$ / \mathrm{MW}$. The simulation on this network will take place in for cases; in DC and AC OPF and by increasing $\Delta \lambda$ one time $1 \$ / \mathrm{MW}$ and next $30 \$ / \mathrm{MW}$.

The amount of monopolistic production capacity of each generator is shown in table I.
TABLE I

THE AMOUNT OF MONOPOLISTIC PRODUCTION CAPACITY OF EACH GENERATOR

\begin{tabular}{|c|c|c|c|c|c|c|c|}
\hline & $\Delta \lambda$ & G1 & G2 & G3 & G4 & G5 & G6 \\
\hline \multirow{2}{*}{$\begin{array}{l}\text { DC } \\
\text { OPF }\end{array}$} & $\begin{array}{l}1 \\
\$ / \mathrm{MW}\end{array}$ & 0 & 0 & 0 & 0 & 4.9995 & 13.8255 \\
\hline & $\begin{array}{l}30 \\
\$ / \mathrm{MW}\end{array}$ & 0 & 0 & 0 & 0 & 4.9995 & 13.8255 \\
\hline \multirow{2}{*}{$\begin{array}{l}\mathrm{AC} \\
\mathrm{OPF}\end{array}$} & $\begin{array}{l}1 \\
\$ / M W\end{array}$ & 0 & 0 & 12.98 & 23.865 & 25.5975 & 42.1982 \\
\hline & $\begin{array}{l}30 \\
\$ / \mathrm{MW}\end{array}$ & 0 & 0 & 0 & 0 & 7.4967 & 18.7562 \\
\hline
\end{tabular}

For DC OPF the results show the exact amount of monopolistic production capacity, because there is no loss or any thermal and reactive limitation in transmission lines. Since losses are neglected in this simulation when using the DC model, the size of the price change $\Delta \lambda$ should have no impact on the resulting. To investigate the changes of these suppliers output while increasing $\Delta \lambda$, we increase it as stepwise from $1 \$ / \mathrm{MW}$ to $30 \$ / \mathrm{MW}$. By increasing this price the output active power of each generator will be decreased, but the figure 5 shows that by continuing this procedure after the prices equal to MPC, the outputs of some of generators do not change. These are the generators which have the potential of exercising market power. In this network they exist in area 2 which is connected to the other areas through congested transmission lines.

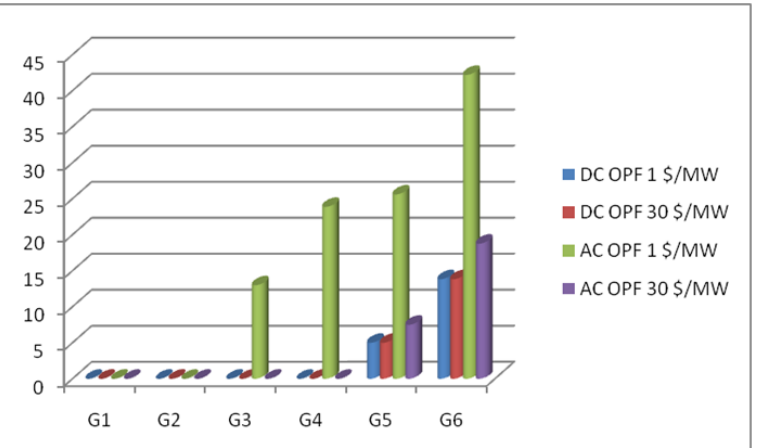

Fig 4. The amount of monopolistic production capacity of each generator
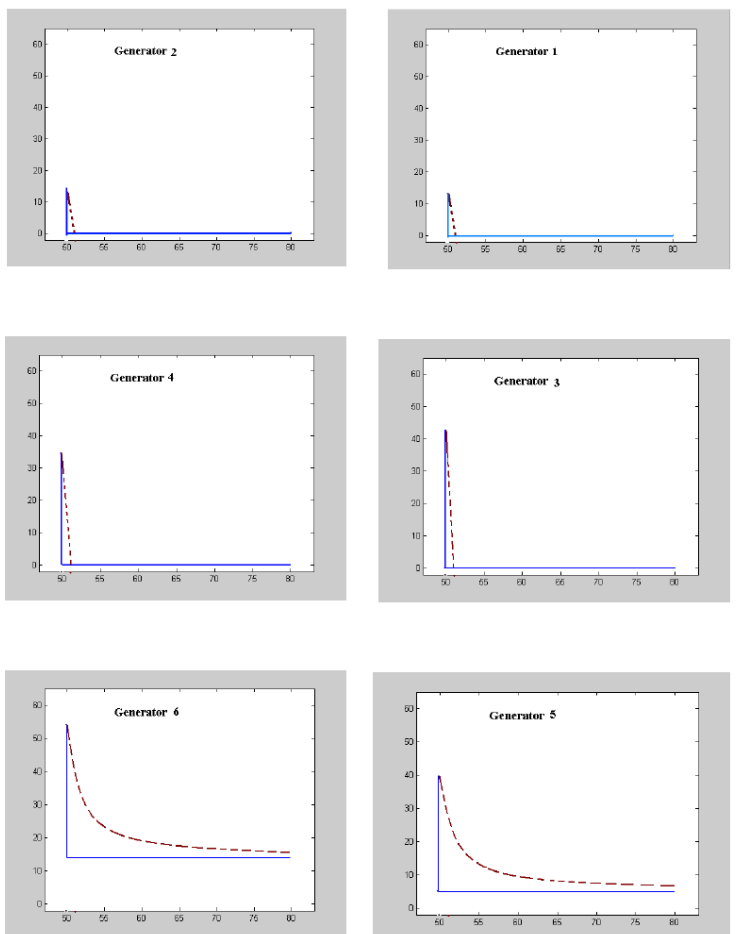

Fig 5. Price increase impact on the amount of different generators 
A stepwise increase of prices in AC OPF model shows that the total load will be decreased either. So in AC OPF the results cannot be true in every situation. So in our "run market" program emphasize that the total load do not change and it must be $195 \mathrm{MW}$. In this condition the amount of $42 \$ / \mathrm{MW}$ has been calculated as $\Delta \lambda$ by which the total demand is constant. The MPC amount of the system generators are shown in table II.

TABLE II

THE MPC AMOUNT OF THE SYSTEM GENERATORS (AC OPF)

\begin{tabular}{|l|l|l|l|l|l|l|}
\hline G & G1 & G2 & G3 & G4 & G5 & G6 \\
\hline MPC & 0 & 0 & 0 & 0 & $\mathbf{2 . 6 5 0 3}$ & $\mathbf{1 8 . 7 0 2 3}$ \\
\hline
\end{tabular}

Since existence of MPC is a direct result from congestions in the network, there should still be some significant similarities when comparing usage of the two mentioned power flow models. Generally the AC model result was strictly greater levels of MPC, in comparison to the corresponding calculations using the DC model. This difference should be due to the fact that including reactive power will effectively constrict the thermal limits of the transmission lines even further. Also losses might play a role in this, since it should logically cause an elevation in generation.

In order to investigate the impact of transmission constraint on the amount of monopolistic production capacity the thermal limits of the line between buses 4-12 and 23-24 have been decreased. The thermal limits of the line between bus 4 and bus 12 is $10 \mathrm{MW}$ and between 23 and 24 is $5 \mathrm{MW}$. Results are shown in figure 6.

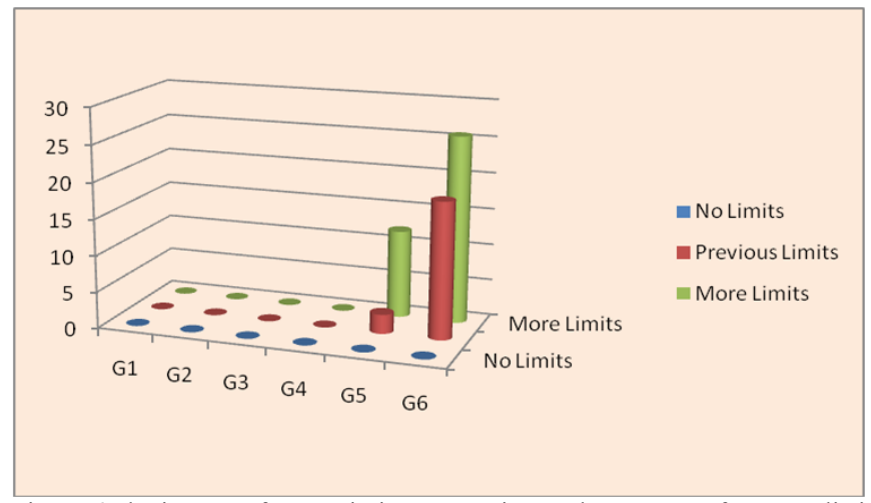

Figure 6 . the impact of transmission constraint on the amount of monopolistic production capacity

\section{B. Confirmation of above results by market power indices}

Strategic behavior in the market is modeled throughout a game in which the producers bid to maximize their profits The strategic bidding model is based on a supply function model in which the producers decide the offers to maximize their surpluses. Behavior of each producer, i.e., his/her offer function $\rho_{g}$, is here characterized by an increase over the linear marginal cost curve $M_{g}$ :

$$
\begin{aligned}
& M_{g}=c_{g}^{m}+\frac{1}{\eta_{g}} P_{g} \\
& \rho_{g}=c_{g}+\frac{1}{\eta_{g}} P_{g}
\end{aligned}
$$

$c_{g}^{m}$ : Intercept of the marginal cost curve of producer $\mathrm{g}$.

$\eta_{g}$ : Reciprocal of the slope of the offer curve and the marginal cost curve of producer $\mathrm{g}$.

$P_{g}:$ Power of producer $\mathrm{g}$.

$\rho_{g}$ : Price for producer $\mathrm{g}$.

$c_{g}$ : Intercept of the offer curve for producer $g$

Hence the supply function and the marginal cost are parallel, differing only for the term $c_{g}$ The payoff of the game is measured by the producer surplus of each producer. The demand curve for load is also assumed linear

$D_{d}=d_{d}^{o}-d_{d}^{k} D_{d}$

$D_{d}:$ Power for load d

$d_{d}^{o}$ : Load quantity at zero price for load $\mathrm{d}$

$d_{d}^{k}$ : Price sensitivity of load d.

Each player will start the game using $\mathrm{cg}=\mathrm{cg}^{\mathrm{m}}$ at each move, a player, in turn, will maximize his/her surplus $S^{G}$ choosing the best cg and taking the last offers of the competitors as given. The $\mathrm{S}_{\mathrm{g}}^{\mathrm{G}}$ achieved by a producer would depend on the outcome of the market dispatch to maximize the system

surplus1 undertaken, under network constraints, by the independent system operator (ISO). This procedure can be formulated in terms of the following optimization problem:

$$
\begin{aligned}
& \max S^{y}=\sum_{d \in D}\left(\frac{d_{d}^{o}}{d_{d}^{k}}-\frac{1}{2 d_{d}^{k}} D_{d}^{2}\right)-\sum_{g \in \varsigma}\left(c_{g} P_{g}+\frac{1}{2 \eta_{g}} P_{g}^{2}\right) \\
& \text { s.t. } \eta(.)=\sum_{d \in D} D_{a}-\sum_{g \in \varsigma} P_{g}=0 \leftarrow \lambda \\
& g_{l}^{+}(.)=F_{l}-F_{l}^{M} \leq 0, \quad l=\{h, k\} \in \mathrm{Z} \leftarrow \mu_{l}^{+} \\
& g_{l}^{-}(.)=-F_{l}-F_{l}^{M} \leq 0, \quad l=\{h, k\} \in \mathrm{Z} \leftarrow \mu_{l}^{-} \\
& g_{g}^{\max }(.)=P_{g}-P_{g}^{\max } \leq 0 \leftarrow \mu_{g} \\
& g_{g}^{\min }(.)=0-P_{g} \leq 0
\end{aligned}
$$

Performance and price index:

$K_{s}=\frac{S-S^{*}}{S^{*}}=\frac{\Delta S}{S^{*}} \times 100$.

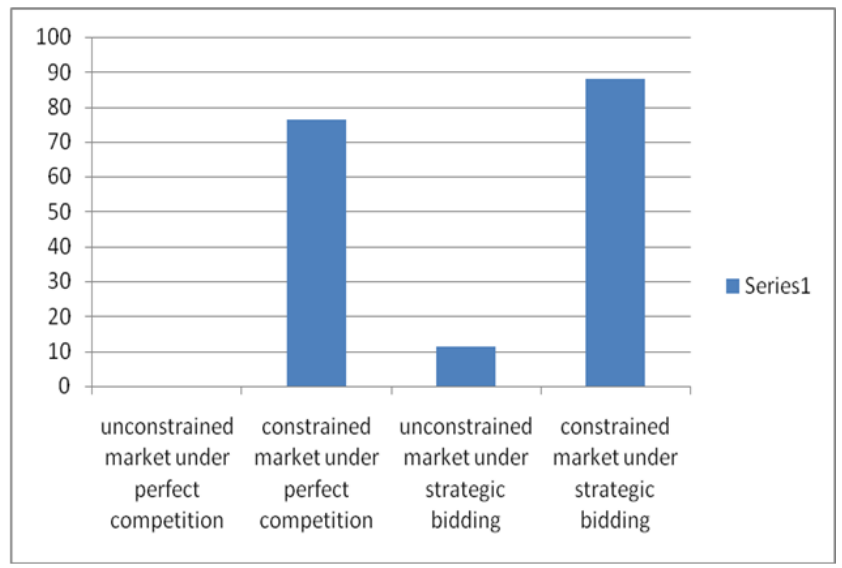

Figure 7. Performance and price index

$M_{g}:$ Marginal cost for producer $\mathrm{g}$. 


\begin{tabular}{|c|c|c|c|c|c|c|c|}
\hline \multirow{2}{*}{ Generators } & \multirow{2}{*}{ Locational Prices } & \multicolumn{2}{|c|}{ G1 increase its price } & \multicolumn{2}{|c|}{ G3 increase its price } & \multicolumn{2}{|c|}{ G5 increase its price } \\
\hline & & NMP & LI & NMP & LI & NMP & $\mathrm{LI}$ \\
\hline 1 & 50 & 50 & 0 & 50 & 0 & 50 & 0 \\
\hline 2 & 50 & 50 & 0 & 50 & 0 & 50 & 0 \\
\hline 3 & 50 & 50 & 0 & 51 & 0.02 & 50 & 0 \\
\hline 4 & 50 & 50 & 0 & 50 & 0 & 50 & 0 \\
\hline 5 & 50 & 50 & 0 & 50 & 0 & 65 & 0.30 \\
\hline 6 & 50 & 50 & 0 & 50 & 0 & 62 & 0 \\
\hline
\end{tabular}

As it is shown in table III, the generator which exist in area 2 exert market power by bidding strategy. So the MPC could detect the potential of market power. This conclusion is shown by HHI either:

HHI Index:

$$
H H I_{s}=5208.8677
$$

$\mathrm{HHI}>1800$

\section{CONCLUSIONS}

When there is congestion, it segregates electricity market, and the generating capacities in the congested area will be in relative scarcity. As it is shown in the last section the conventional market power indices confirm the results of the algorithm. The bidding strategies may cause unexpected effects on system; exercising the market power mitigation methods without considering bidding strategies is not efficient. The network impact depends on the actual structure of the grid and on the distribution and types of the generators as far as they impact on the price and available capacity at different locations.

\section{REFERENCES}

[1] Ettore Bompard, Yuchao Ma, Roberto Napoli, and Graziano Abrate, " The Demand Elasticity Impacts on the Strategic Bidding Behavior of the Electricity Producers," IEEE TRANSACTIONS ON POWER SYSTEMS, VOL. 22, NO. 1, FEBRUARY 2007

[2] Ettore Bompard, , Wene Lu, and Roberto Napoli, "Network Constraint Impacts on the Competitive Electricity Markets Under Supply-Side Strategic Bidding", IEEE TRANSACTIONS ON POWER SYSTEMS, VOL. 21, NO. 1, FEBRUARY 2006

[3] Daniel Kirschen and Goran Strbac, "Fundamentals of Power System Economics", 2004 John Wiley and Sons Ltd.

[4] Frank Wolak. Lessons from International Experience with Electricity Market Monitoring, June 2004, CSEM working paper 134, URL: http://www.ucei.berkeley.edu/PDF/csemwp134.pdf.

[5] J. Nicolaisen, V. Petrov, and L. Tesfatsion, "Market power and efficiency in a computational electricity market with discriminatory double-auction pricing," IEEE Trans. Evol. Comput., vol. 5, no. 5, pp. 504-523, Oct. 2001.

[6] E. Bompard, E. Carpaneto, G. Chicco, and R. Napoli, "Reactive load modeling impacts on nodal prices in pool model electricity markets," in Proc. IEEE Power Eng. Soc. Summer Meeting, Seattle,WA, Jul. 14-16, 2000, pp. 150-2155.
[7] E. Bompard, E. Carpaneto, G. Chicco, and G. Gross, "The role of load demand elasticity in congestion management and pricing," in Proc. IEEE Power Eng. Soc. Summer Meeting, Seattle, WA, Jul. 14-16, 2000, pp. 22292234.

[8] P. Marannino, R. Vailati, F. Zanellini, E. Bompard, and G. Gross, "OPF tools for optimal pricing and congestion management in a two sided auction market structure," in Proc. IEEE Power Tech, vol. 1, Porto, Portugal, Sep. 10-13, 2001.

[9] G. Hamoud and I. Bradley, "Assessment of transmission congestion cost and locational marginal pricing in a competitive electricity market," IEEE Trans. Power Syst., vol. 19, no. 2, pp. 769-775, May 2004.

[10] H. Chen and C. A. Canizares, "Transaction impact analysis and its application in electricity markets," in Proc. Power Engineering Large Engineering Systems Conf., May 7-9, 2003, pp. 2-6.

[11] J. Yang and G. Jordan, "System dynamic index for market power mitigation in the restructuring electricity industry," in Proc. IEEE Power Eng

Soc. Summer Meeting vol. 4, Jul. 16-20, 2000, pp. 2217-2222.

[12] E. J. Anderson and A. B. Philpott, "Optimal offer construction in electricity market," Math. Oper. Res., vol. 27, pp. 82-100, 2002.

[13] J. W. Lamont and S. Rajan, "Strategic bidding in an energy brokerage," IEEE Trans. Power Syst., vol. 12, no. 4, pp. 1729-1733, Nov. 1997.

[14] C. A. Li, A. J. Svoboda, X. Guan an, and H. Singh, "Revenue adequate bidding strategies in competitive electricity markets," IEEE Trans. Power Syst., vol. 14, no. 2, pp. 492-497, May 1999.

[15] D. Zhang, Y. Wang, and P. B. Luh, "Optimization based bidding strategies in the deregulated market," in Proc. IEEE Power Industry Computer Applications Conf., May 16-21, 1999, pp. 63-68.

[16] P.Visudhiphan and M. D. Ilic, "Dynamic games-based modeling of electricity market," in Proc. IEEE Power Eng. Soc. Winter Meeting, vol. 1, New York, Jan. 31-4 Feb. 1999, pp. 274-281.

[17] F. S. Wen and A. K. David, "Optimal bidding strategies and modeling of imperfect information among competitive generators," IEEE Trans. Power Syst., vol. 16, no. 1, pp. 15-21, Feb. 2001

[18] L. Yang, F. Wen, F. F. Wu, Y. Ni, and J. Qiu, "Development of bidding strategies in electricity markets using possibility theory," in Proc. Power System Technology Conf., vol. 1, Oct. 13-17, 2002, pp. 182-187.

[19] Martin Elfstadius and Daniel Gecer, "Method to Detect and Measure Potential Market Power Caused by Transmission Network Congestions on Electricity Markets", LITH-ISY-EX--08/4033-SE, April 2008.

[20] P. R. Kleindorfer, D. J. Wu, and C. S. Fernando, "Strategic Gaming in electric power markets," in Proc. 33rd Annu. Hawaii Int. Conf. System Sciences, Jan. 4-7, 2000, pp. 1345-1354.

[21] H. Singh, "Introduction to game theory and its applications in electric power markets," IEEE Comput. Appl. Power, vol. 12, no. 4, pp. 18-22, Oct. 1999.

[22] E. Bompard, F. Italiano, R. Napoli, and E. Ragazzi, “An IPV auction model for strategic bidding analysis under incomplete and asymmetric information," in Proc. 13th Conf. Intelligent Systems Application Power Systems, Aug. 31 -Sep. 3, 2003.

[23] Z. Younes and M. Ilic, "Generation strategies for gaming transmission constraints: Will the deregulated electric power market be an oligopoly?," in Proc. IEEE Hawaii Int. Conf. System Science, vol. 3, Jan. 6-9, 1998, pp. $112-121$ 